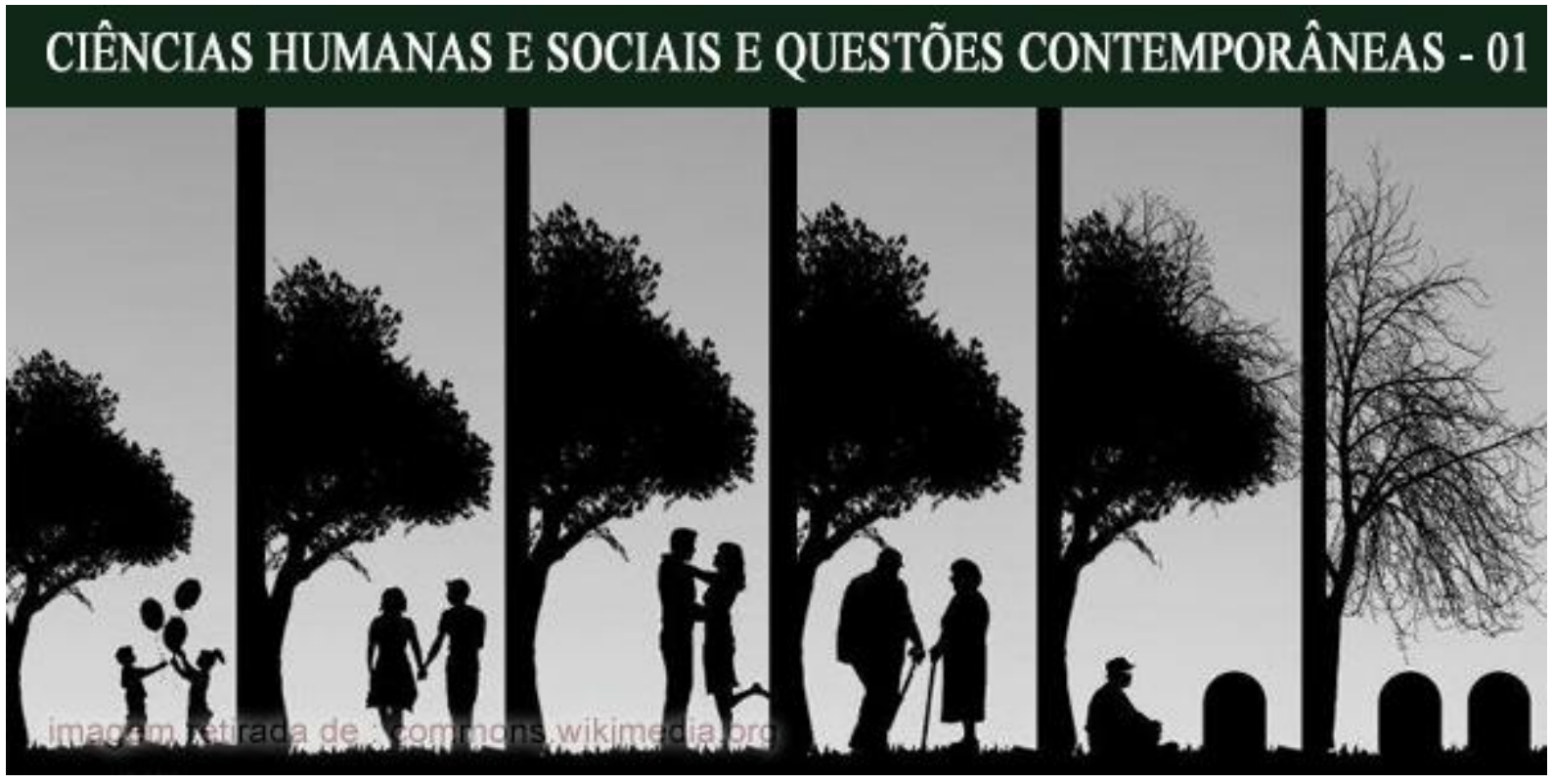

\title{
DIÁlogos ENTRE A MORTE E A AUTOLEGITIMAÇÃO DA VIDA
}

\author{
Alexandra de Gouvêa Vianna \\ ORCID: https://orcid.org/0000-0001-9539-9760. \\ E-mail:agvianna@gmail.com.

\section{Bruno Latini Pfeil \\ ORCID: https://orcid.org/0000-0002-2252-6834.}

Resumo: Este artigo objetiva uma melhor compreensão da morte a partir do fenômeno do suicídio. O suicídio se apresenta como um analisador desta discussão, pois compreende-se como a fuga, pela morte, a uma aniquilação presente em vida. O artigo se utiliza, principalmente: dos estudos de Karl Menninger (1938/2018) sobre comportamentos autodestrutivos, tais como automutilação e acidentes propositais; da experiência de Elisabeth Kluber-Ross (1969/1981) com pacientes terminais e de suas impressões sobre a lida de pessoas próximas e da equipe médica desses pacientes com o estreitamento da morte; e da análise de Maria Julia Kovács (1992) acerca da morte durante o desenvolvimento humano, bem como das mudanças de significação do corpo morto, no decorrer dos séculos; juntamente com demais autores para complementar a sustentação teórica do artigo. Com eles, argumenta-se que os comportamentos autodestrutivos buscam, muitas vezes, a preservação do sujeito, ao invés de seu total aniquilamento, e que a retirada da morte de seu lugar inacessível na cultura é uma das possíveis formas de evitá-la. A partir disso, conclui-se que a preservação da vida a todo custo promove mais morte do que vida e aniquilamento de subjetividade, que poderia ser considerada uma morte em vida, como nos dirá Kovács (1992). A evitação da morte propõe sua negação e mudez em torno de comportamentos supostamente destrutivos relacionados a ela.

Palavras-chave: Suicídio. Morte. Autoaniquilamento.

\section{DIALOGUES BETWEEN DEATH AND THE SELF-LEGITIMATION OF LIFE}

Abstract: This article intends to provide a better understanding of death through the phenomenon of suicide. Suicide presents itself as an analyzer of this discussion, once it is read as the escape, through death, from an annihilation of life. In this article, it is mainly used Karl Menninger's (1938/2018) studies on self-destructive behaviors, such as self-mutilation and purposed accidents, Elisabeth Kluber-Ross' (1969/1981) experience with terminally ill patients and her impressions about the way the closed ones and the medical staff of the patients deal with the narrowing of death, and Maria Julia Kovács' (1992) analysis over death during the human development

\section{POLÊM!CA $\mid$ LABORE}

Polêmica - Revista Eletrônica da Uerj - Rua São Francisco Xavier, 524, $1^{\circ}$ andar bloco D, sl.1001 • Tels.: +55 21 2334-4088 / 4087 • http://www.e-publicacoes.uerj.br/index.php/polemica/index http://www.labore.uerj.br•llaboreuerj@yahoo.com.br 
and the changes of the significations of the dead body throughout the centuries, along with other authors. With them, it is argued that self-destructive behaviors often seek the preservation of the subject rather than its total annihilation, and that the removal of death from its inaccessible and denied place in culture is one of the possible ways to avoid it. Finally, it is concluded that the preservation of life at all costs promotes more death than life and annihilation of subjectivity, that could be considered a death in life, as Kovács (1992) will report. The avoiding of death proposes its denial and muteness around supposedly destructive behaviors related to it.

Keywords: Suicide. Death. Self-annihilation.

\section{Introdução}

Este artigo pretende, com o título Diálogos entre a morte e a autolegitimação da vida, criar um espaço de reflexão sobre o tema deste trabalho, qual seja, a morte, ao contrário de uma tentativa - geralmente falha - de se impor determinismos. Falar da morte requer algumas contravenções: primeiro, retirá-la do seu lugar aversivo, resultado de insurgências sociais sobre as quais falaremos nesta introdução; segundo, referenciá-la ao seu oposto, a vida, questionando o frágil limite entre essas duas instâncias e, por último, a luta pela vida por meio do distanciamento da morte.

O título deste trabalho não pretende somente fomentar reflexões entre nós, vivos, sobre o morrer e o viver. Busca-se o diálogo da morte com a vida. No decorrer da estruturação deste trabalho, a aproximação dessas duas experiências foi intimamente necessária, em vez de afastálas como se não pertencessem uma à outra. Procurou-se, no suicídio, um analisador desta narrativa, em decorrência de seu caráter avesso a qualquer representação da morte em nossa cultura. Como será compreendido com mais profundidade, a morte, em nossa sociedade, é repulsiva, distanciada e encoberta, sendo o suicídio o total oposto dos discursos referentes à vida e ao falecimento.

Nesta introdução, será abarcado o assunto da morte, inicialmente, para depois focalizar no término voluntário da vida. Antes de pôr à prova nossa lida com a morte, deve-se conceituála e analisar os motivos pelos quais ela é representada de forma tão aversiva para nossa sociedade. Um dos motivadores para o desenvolvimento deste trabalho advém da hipótese de que a dificuldade de se lidar com a morte interfere na escuta clínica e na produção acadêmica sobre o tema. Quando a causa da morte é o suicídio, tal dificuldade cresce drasticamente, considerando as contradições que o suicídio implica na lógica de aversão e mascaramento atribuída à morte. Profissionais da saúde, por exemplo, pelo receio de efeitos negativos de uma fala sobre o suicídio, poderiam inibir que a pessoa elabore o seu discurso sobre o morrer e o viver, a partir da imposição de crenças e de dificuldades pessoais para com a proximidade da morte. Essa inibição, como será elaborado ao longo do texto, não impede que um suicídio

\section{POLÊM!CA | LABORẸ}

Polêmica - Revista Eletrônica da Uerj - Rua São Francisco Xavier, 524, $1^{\circ}$ andar bloco D, sl.1001 • Tels.: +55 21 2334-4088 / 4087 • http://www.e-publicacoes.uerj.br/index.php/polemica/index http://www.labore.uerj.br • laboreuerj@yahoo.com.br 
ocorra, pelo contrário: impede a livre expressão do sujeito sobre o sofrimento que o leva a tal ato.

As crenças que atravessam uma possível escuta clínica e que moldam a forma com que o suicídio será encarado por familiares e conhecidos, e pelo próprio sujeito que o tentou, somente podem ser pensadas a partir de determinado contexto histórico, de um dado território e das dinâmicas sociais específicas que influem na vida do sujeito. Parte-se da concepção de que a significação da morte está atrelada aos contextos culturais distintos. O caráter cultural é aprofundado por Maria Júlia Kovács (1992) em seus estudos sobre a presença da morte no desenvolvimento do sujeito. A representação da morte na experiência humana reflete tanto uma invariabilidade essencial quanto uma relatividade cultural. Invariável, pois, embora a imortalidade seja subjetivamente buscada, a consciência objetiva denuncia nossa finitude; relativa, quando os significados da morte, em diferentes culturas, definem a forma como se lida com ela. Lida-se, portanto, não com a morte em si, mas com suas representações, visto que tudo é filtrado pela ótica cultural e pelo horizonte histórico de determinadas épocas e localidades.

Pode-se encontrar, nos cemitérios, exemplos destas modificações dentro de nossa cultura. Na Idade Média, as sepulturas localizavam-se nas igrejas como uma forma de proteção. Igrejas e cemitérios, denominados originalmente de churchyards (em tradução livre, "quintais de igrejas"), alocavam-se nos centros das cidades (KOVÁCS, 1992). Com o crescimento populacional, os cemitérios saíram dos limites da cidade pelas preocupações com salubridade e epidemias:

O corpo morto passa a ser escondido, pois é insuportável para os olhos. Os caixões são usados para esconder o corpo. O embalsamamento, ritual tão antigo, continua a ser usado como forma de conservar viva a imagem do morto, sem dúvida uma forma de negar a morte (KOVÁCS, 1992, p. 33).

A localização dos cemitérios à margem e não ao centro, o distanciamento da dinâmica social ao corpo morto pelas epidemias e a necessidade de higienização refletem na relação das pessoas com a morte. Esta encontra-se também à margem, evitada. Adquire uma imagem de podridão e repulsa, perde seu intuito familiar e emocional para o controle epidêmico/médico. O doente representa a mortalidade humana, característica que, segundo Kovács, as pessoas negam tanto no nível simbólico quanto no material. A vida deve prevalecer a todo custo e, se padecer, o fracasso deve ser escondido o mais longe possível, pois denuncia não só a morte do doente, mas a mortalidade humana.

\section{POLÊM!CA $\mid$ LABORE}


Da mesma forma com que os mortos são transferidos do centro à margem, os doentes se deslocam dos lares aos hospitais (KOVÁCS, 1992). O hospital esconde a morbidade da doença, afasta os familiares e impede o convívio social. O silêncio do ambiente médico deve ser preservado, como se a interação social com os pacientes impulsionasse choros e lamentações, visibilizando novamente a morte. Com a chegada do século XX, questões como a medicalização compulsória, a "morte em vida" e o controle dos corpos vêm à tona.

Como diz Kovács, o século XIX emergiu com as tentativas de higienização pelas recorrentes epidemias, como a realização de decretos para determinar a profundidade mínima das covas. O século XX traz "a morte que se esconde, a morte vergonhosa [...], [que] não pertence mais à pessoa, tira-se a sua responsabilidade e depois a sua consciência" (KOVÁCS, 1992, p. 38). Expulsa-se a morte para proteger a vida, de forma que o corpo morto seja pintado, corado e devidamente vestido, configurando a morte perfeita. "A morte 'boa' é aquela em que não se sabe se o sujeito morreu ou não" (KOVÁCS, 1992, p. 38). E o luto bom é aquele em que o sujeito se encontra ensimesmado por estar internamente processando sua perda, porém sem possibilidade de expressá-la. Embora aparentemente silencioso, esse sujeito pode estar gritando e se maltratando por culpa e ódio. Aqui, considera-se significativo ressaltar que o silêncio manifesto advém da educação por uma norma cultural na qual os enlutados precisam se calar. Há uma supressão do luto, a impossibilidade de se vivenciar a dor, a exigência de controle (KOVÁCS, 1992), pois a expressão de sentimentos referentes à perda expõe a proximidade da morte.

Mapeia-se, em nossa cultura, as representações da morte, os tabus e os rituais, a fim de delinear com o máximo de precisão o sentido que o suicídio tem em nosso trabalho. É possível encontrar referências à morte no Goticismo, por exemplo, muitas vezes de forma "peculiar" e trevosa. Contudo, esses modos de ser caracterizam-se mais como uma forma de lidar com a vida do que como uma aproximação da morte. Se a leitura social da morte é exatamente seu apagamento, pode-se compreender o suicídio como a contravenção mais extrema a esse silêncio; um verdadeiro grito. Delimitados dois campos de análise, a lida com a vida e a busca pela morte, este artigo estuda o impacto do fenômeno de provocar - ou não - o fim de uma experiência - ou uma nova experiência - em nossa lida com a morte, e o que comportamentos supostamente destrutivos têm a dizer sobre as concepções atuais referentes a eles.

\section{POLÊM!CA $\mid$ LABORE}


Além do desligamento dos sentidos, da passagem de um plano para o outro ou da ausência de vida no corpo, a morte é concebida como radicalidade, refazimento espontâneo, absurdo. Neste trabalho, a morte é pensada como um momento de pura exposição e vulnerabilidade, em que o corpo se entrega à inevitabilidade, à impossibilidade de auto sustentação.

A consciência da nossa morte denuncia nosso anseio. Levando em conta os processos que conduziram o sujeito a determinado fim, deve-se questionar, antes, o que é a vida. As possíveis respostas a isso são elaboradas com infinitos limites. A vida e a morte podem ser lidas como experiências. Conclui-se que a diferença primordial entre - o que entendemos como - a vida e - o que se entende como - a morte é uma mudança radical de estado. Há realmente o fim de uma linha, mas não necessariamente uma única morte. Contextualizando para o tema em questão, não há um único suicídio.

Em seu livro Eros e Tânatos: o homem contra si próprio, Menninger (1938/2018) divide o suicídio em três categorias: o suicídio crônico, o suicídio focal e o suicídio orgânico.

No que diz respeito ao suicídio crônico, Menninger o define como um "suicídio em polegadas", em que o sujeito adquire "variados e engenhosos recursos para prolongar a existência com o propósito de sofrer mais privações" (1938/2018, p. 101), como no caso do ascetismo. Para isso, o sujeito precisa atenuar as punições que provoca a si próprio. $\mathrm{O}$ ascetismo, o martírio e o comportamento antissocial são alguns exemplos de suicídios crônicos analisados por Menninger. De forma geral, no suicídio crônico, o sujeito "adia a morte indefinidamente, à custa de sofrimento e diminuição de função, o que é equivalente a um suicídio parcial - uma 'morte em vida' é verdade, mas ainda assim vida" (MENNINGER, 1938/2018, p. 102).

O suicídio focal concentra-se no corpo, ou melhor, em uma parte limitada do corpo. A focalização desta categoria de suicídio ocorre mediante o aniquilamento de uma parte do corpo pelo todo, como será explicado adiante. Automutilação, acidentes inconscientemente propositais e simulação de doença são exemplos dessa categoria (MENNINGER, 1938/2018, p. 243).

O suicídio orgânico, por sua vez, se utiliza de recursos internos contra um ajustamento inadequado a vida. Como apontado no texto de Menninger: se existem "propósitos inconscientes no impulso de arrancar o próprio olho ou cortar a própria orelha", como no

\section{POLÊM!CA $\mid$ LABORE}


suicídio focal, "não será possível que os mesmos propósitos profundos às vezes encontrem expressão através de mecanismos fisiológicos em doenças que atacam o olho ou o ouvido?" (MENNINGER, 1938/2018, p. 367). Esta categoria se configura como a promoção inconsciente de doenças e complicações fisiológicas, comumente sem origem definida, e que atuam como pequenas mortes na lida do sujeito com seu cotidiano. Apesar da extensão do estudo dos suicídios e de suas diferentes categorias, este trabalho se atém à investigação das automutilações e de seus fatores autodestrutivos.

No que diz respeito à autodestruição, os estudos de Freud (1915/1996a) sobre a constituição do sujeito em cima do ódio são de grande valia. Os componentes do suicídio elaborados por Menninger (1938/2018) dispõem de uma agressividade latente que necessita de aprofundamento. A partir de Freud (1915/1996a) e Fink (1998), investigar-se-ão os pormenores da automutilação, enquanto suicídio parcial.

A automutilação é de grande ajuda no entendimento dos comportamentos autodestrutivos. Para Menninger (1938/2018), apesar de sua evidente destrutividade orgânica e de suas deliberações autopunitivas, a prática da automutilação exprime uma tentativa de permanecer vivo, ao invés de promover o total aniquilamento. Fink (1998) contribui para a compreensão das práticas autopunitivas como resultados culturais. Com ele e Menninger, compreende-se que as punições obtidas pela automutilação somente expiam práticas socialmente condenáveis - no caso estudado, a masturbação -, inferindo na substituição dos genitais por outra parte erogeneizada do corpo e no desejo de autocastração, como será elaborado no próximo tópico deste artigo.

Dessa forma, se a morte ocorre diversas vezes durante a vida - tomando como exemplo o suicídio focal - e como ruptura e radicalidade - o suicídio agudo, em que o ato geralmente se consuma de forma violenta - e se a vida é um processo de realização constante dessas radicalidades, para que haja a ruptura proclamada pela morte, deve haver, então, uma base comum sedimentada, denominada cultura. Não é possível pensar as automutilações e, com isso, os diferentes suicídios, desconsiderando nosso arcabouço cultural, como já disse Kovács (1992).

Elisabeth Kluber-Ross (1969/1981), discorrendo sobre a morte e o morrer, mostra como a lida com pacientes em fase terminal impacta a família, os médicos e os demais entornos. A medicalização compulsória mostra-se, nesse caso, como uma barreira contra as trocas de afeto,

\section{POLÊM!CA $\mid$ LABORE}


a aceitação da morte pelo sujeito, ou melhor, um diferente entendimento da morte, do morrer e da vida. Por que velar tanto um momento inevitável, adiá-lo ao máximo a ponto de provocar uma "morte em vida"? Com Kluber-Ross, vê-se a morte como uma experiência que abarca toda uma rede de relações e a aceitação da morte como a melhor possibilidade, dentre as que conhecemos, para se viver uma vida plena. Nesse contexto, o suicídio se apresenta totalmente avesso às normas sociais, considerando o caráter de negação e evitação da morte expressado tanto por pacientes terminais, quanto pela rede médica, familiar e social que os rodeia, como demonstrado por Kluber-Ross.

O estudo do fenômeno do suicídio requer desde a compreensão das variabilidades cultural e geográfica, que modificam as dinâmicas sociais e as formas com que o suicídio é tentado ou cometido, até a investigação dos diferentes tipos de suicídio, seja este focal, crônico ou orgânico, segundo os modelos de Menninger (1938/2018). Neste artigo, procura-se compreender o fator autodestrutivo dos suicídios e das práticas que o abarcam como um analisador da morte. Seguindo essa linha de raciocínio, surge a seguinte questão: como compreender o fenômeno do suicídio enquanto forma de autolegitimação da vida?

\section{Argumentação}

O tabu da morte é aspecto central para a nossa concepção de suicídio; um tabu repleto de emoções reprimidas e temores projetivos. O suicídio é, geralmente, desconsiderado como uma opção, privando-o de seu lugar na realidade e evitando a responsabilidade do ato. Pelo contrário, ele é concebido como consequência de desânimo, transtorno mental e frustração, delimitando explicações simplistas e incompletas para esse fenômeno. O suicídio é lido erroneamente como fuga a um fator específico e facilmente localizável na vida.

Pode-se encontrar, em Menninger (1938/2018), asserções contrárias a essa simplificação. Para o autor, o sujeito cria, em certa medida, o próprio ambiente que o mata, a coisa da qual foge, nem que esta se configure como ele mesmo. A fuga de si requer o auto aniquilamento escancarado: a tolerabilidade da vida seria calcada na não-existência. Nesse sentido, não é possível atribuir significações simplistas ao fenômeno do suicídio, da mesma forma com que não se pode descrever em uma linha a total constituição do sujeito. Para a compreensão plena do que leva uma pessoa a suicidar-se, deve-se considerar sua relação com a morte, e não unicamente com a vida.

\section{POLÊM!CA $\mid$ LABORÉ}


Considerando a complexidade da constituição do sujeito e os fatores que o levaram a finalizar sua existência, o suicídio é caracterizado tal qual um processo. Na medida em que o sujeito se depara com a escolha primordial (continuar a viver), ele atravessa e tolera as mais variadas e angustiantes - ou alegres! - formas de suportar a finalização de sua existência. O suicídio é um processo na medida em que sua finalização está arraigada na vida. Na realidade, por um viés ainda mais radical, pode-se pensar que a vida, a morte e a existência não se dissociam em nenhum momento, mas constituem, simplesmente, uma experiência contínua na consciência. Por essa lógica, todas as mortes são suicidas.

De forma mais geral, o suicídio reflete uma passagem, mesmo que não haja destino possível do outro lado da linha, se houver alguma. O suicídio é uma linha de fuga - fuga de quê? Se a morte está embebida em significações culturais (ou, ainda, se a morte é em si uma significação), tem-se que o suicídio, ao romper com tais significações, é uma fuga às imposições da cultura. Tanto a existência quanto a possibilidade de inexistência exprimem a insuportabilidade, o absurdo. O suicídio é aqui compreendido como o significante do absurdo, impossível de ser racionalmente mensurado.

Para Menninger (1938/2018), “o suicídio é também um homicídio por si próprio” na medida em que é compreendido como "uma morte na qual estão combinados em uma só pessoa o assassino e o assassinado" (p. 39). No decorrer de seu raciocínio, o autor destaca três elementos regentes do suicídio: o desejo de matar, o desejo de morrer e o desejo de ser morto.

O desejo de matar obedece à agressividade primária do sujeito, à destrutividade impelida pela privação. Desprovido de objetos para os quais o sujeito direcionaria sua vontade, o desejo destrutivo de matar "pode voltar-se para a pessoa de 'quem deseja' e ser executado como suicídio" (MENNINGER, 1938/2018, p. 46). Destaca-se, também, a semelhança do desejo de matar com a ideia de que o sujeito suicida pretende eliminar certa tristeza, um aspecto circunscrito de si ou de sua vida, aniquilando, para esse fim, todo o seu ser. Brevemente, no que diz respeito ao desejo de matar, tem-se que a repentina retirada ou infidelidade de um ou vários objetos de desejo desloca o impulso homicida, para que ele se aplique sobre a origem da pulsão - o sujeito - como objeto substituto. Tal ideia, apesar de cabível em certas situações, restringe a experiência do sujeito a uma pequena quantidade de objetos.

Em referência ao instinto destrutivo como pulsão de morte, distingue-se o desejo de matar. Em As pulsões e suas vicissitudes (1915/1996a), Freud compreende o ódio como uma

\section{POLÊM!CA $\mid$ LABORE}


reação do sujeito frente a objetos desagradáveis. Uma vez fora do útero, o bebê se encontra à mercê das intempéries do mundo: o frio, a fome, o alargamento do intestino. A primeira coisa que ele sente é o desprazer: o bebê sai de um estado sem estímulos para um estado de desejo, e não somente as referências culturais a ele embutidas. Há necessidades fisiológicas que exigem satisfação e, para que elas sejam saciadas, é preciso haver, primeiro, um alerta que as denuncie: o choro.

O eu odeia, abomina e persegue, com intenção de destruir, todos os objetos que constituem uma fonte de sensação desagradável para ele, sem levar em conta que significam uma frustração quer da satisfação sexual, quer da satisfação das necessidades de autopreservação (FREUD, 1915/1996a, p. 160).

Diante disso, o ódio se estrutura a partir de pulsões de autopreservação, na medida em que deriva de uma reação do sujeito contra objetos que promovem desprazer. "Destruição não é fruto do amor, mas do ódio", escreve Menninger (1938/2018, p. 247). Sendo assim, compreende-se o comportamento autodestrutivo como uma tentativa de se autopreservar, contrariando a ideia de que a autodestruição provocaria subsequentemente o autoaniquilamento.

Além disso, o ódio se configura a partir de uma inabilidade do Outro em satisfazer suas demandas. No momento em que o sujeito se constitui enquanto tal, isto é, passa a integrar uma cultura, seus desejos são imediatamente restringidos ao arcabouço simbólico providenciado por ela. Para Fink (1998), a linguagem surge na vida da criança pela necessidade de ir "além do estágio do choro", sendo forçada a adquirir uma forma de expressão compreensível para seus cuidadores. As significações culturais são impostas à realidade infantil como uma alfabetização simbólica: uma vez aprendida, não há como "desalfabetizar-se". Uma vez limitadas ao arcabouço linguístico oferecido por seus cuidadores, as crianças têm seus desejos moldados pelas significações previamente imputadas nas palavras.

Com o advento da linguagem, a necessidade é significada em termos socialmente aceitáveis e compreensíveis, tornando-se, assim, desejo. $\mathrm{O}$ sentido atribuído à necessidade, à causa do frio, da fome e da dor, determina-se pelo que a linguagem entende como frio, fome e dor. Dessa forma, a constituição do desejo ocorre por intermédio do Outro como linguagem.

Nesse sentido, o Outro pode ser visto como um intruso traiçoeiro e não convidado que, sem cerimônia e de maneira desfavorável, transforma nossos desejos, mas é, ao mesmo tempo, aquilo que nos capacita a revelar uns aos outros nossos desejos e a nos 'comunicarmos' (FINK, 1998, p. 23).

\section{POLÊM!CA $\mid$ LABORE}


Compreende-se, assim, que os desejos da criança são moldados pela linguagem, orientando-as de acordo com as imposições e demandas sociais. O que caracteriza o desejo é sua inserção no contexto cultural e sua invariável modelação. O sujeito, portanto, é alienado na linguagem. Da mesma forma com que a linguagem permite a expressão do desejo, ela o restringe em suas limitações discursivas, impossibilitando sua satisfação total.

Com isso, não são somente os desejos dos outros que compõem o inconsciente, mas a reprodução da cultura nas falas dos outros, considerando que a cultura só é reiterada pelas relações sociais. O Outro se constitui das narrativas culturais reproduzidas pelos outros, que sequer percebem que as reproduzem; na verdade, os desejos, fantasias e narrativas impostos culturalmente são naturalizados. Estruturas sociais de dominação não são compreendidas como construídas culturalmente, mas como a reprodução, no social, de determinações naturais. $\mathrm{O}$ Outro é o conjunto de narrativas culturais introjetadas pelo sujeito, que podem causar - e geralmente causam - sofrimento devido à incapacidade do sujeito de exercer totalmente (e com gosto) as funções incumbidas a ele. Daí provém o ódio: pela incapacidade da cultura em abarcar as demandas do sujeito e pela incapacidade do sujeito em suprir as demandas do Outro. $\mathrm{O}$ homicídio é duplo!

Dito isso, o desejo de ser morto torna-se, agora, o assunto a ser tratado. O cultivo de desejos homicidas fomenta, também, a necessidade de autopunição. Observa-se, no desejo de ser morto, a realização dessa necessidade, pois a "punição aplicada a si próprio (por entregarse ao ato) é assim ao mesmo tempo punição daqueles que supostamente interferem no ato" (MENNINGER, 1938/2018, p. 82). O conteúdo erótico, localizado por Menninger na masturbação - em sua representação cultural como desobediência e desvio sexual -, vincula-se intimamente às repressões sexuais que afligem o sujeito.

Essa culpa [pela masturbação] exige punição e, enquanto as práticas auto eróticas são continuadas, a punição é encerrada na satisfação, pois muitos imaginam que a masturbação representa grave perigo para a saúde e para a vida da pessoa, tanto neste mundo como no outro (MENNINGER, 1938/2018, p. 82).

O lugar que a masturbação ocupa na discussão sobre as automutilações, nesse contexto, é bem interessante, visto que muitas das práticas autodestrutivas são adotadas a fim de saciar a culpa.

A assertiva lacaniana de que "o corpo é escrito com significantes" compreende que as funcionalidades da anatomia são indissociáveis dos papéis que lhe foram impostos. A nomeação

\section{POLÊM!CA $\mid$ LABORE}


do corpo enquanto tal pressupõe todas as atribuições sujeitadas a ele, os significados da palavra, os desenhos de sua morfologia. Como usufruir da potencialidade do corpo se sua superfície se limita ao direcionamento das vontades, aos desejos instituídos pela linguagem?

Para Freud, "a libido da criança perversa polimorfa é progressivamente canalizada para [...] zonas erógenas específicas [...] através de demandas, expressas verbalmente, feitas à criança por seus pais e/ou figuras paternas" (FINK, 1998, p. 30). Com isso, pode-se presumir que as zonas erógenas são, também, constituídas discursivamente, no decorrer do desenvolvimento da criança.

Nossas próprias fantasias podem ser estranhas para nós, pois são estruturadas por uma linguagem que é apenas assintótica ou tangencialmente nossa e, no início, elas podem até ser fantasias de outras pessoas [...] (FINK, 1998, p. 30).

Assim, localiza-se a castração como o engendramento da cultura no sujeito, a restrição discursiva da linguagem; em suma, como a deserogenização do corpo em sua totalidade. $\mathrm{O}$ corpo é castrado ao ser impedido de tornar-se erógeno e as áreas erógenas são castradas ao serem limitadas à erogenização.

Menninger (1938/2018) apresenta diversos casos de automutilação decorrentes da culpa por se masturbar. A masturbação obtém extremas condenações. Além de fomentar a criação de lendas, tais como o crescimento de pelos nas mãos de quem se masturba, denunciando visualmente a prática, o tabu da masturbação culminou na criação de cintos de castidade, impedindo o contato do sujeito com sua genitália.

Em seu estudo sobre pacientes psicóticos adeptos à automutilação, Menninger destaca a brutalidade com que eles expressavam desejos de serem castrados ou de se castrarem, em busca da expiação de históricos sexuais deletérios, geralmente localizados na infância. Devido a essa brutalidade prática dos psicóticos providenciada pela suspensão às normas culturais, o estudo do real propulsor das automutilações torna-se ainda mais viável. Assim, Menninger conclui, com base em seus estudos clínicos, que "todas as tentativas de cortar partes do corpo representam tentativas substitutas e, portanto, simbólicas de privar-se da sexualidade, isto é, cortar ou mutilar um órgão que simboliza os órgãos genitais" (MENNINGER, 1938/2018, p. 279).

A severidade das punições as quais a criança é submetida, quando pega se masturbando, produz a forma como ela se reprimirá, ao não cometer novamente tal ato, ou se repreenderá, ao cometê-lo. Compreende-se, com isso, que a condenação da masturbação resulta na tentativa do

\section{POLÊM!CA $\mid$ LABORÉ}

Polêmica - Revista Eletrônica da Uerj - Rua São Francisco Xavier, 524, $1^{\circ}$ andar bloco D, sl.1001 • Tels.: +55 21 2334-4088 / 4087 • http://www.e-publicacoes.uerj.br/index.php/polemica/index http://www.labore.uerj.br • laboreuerj@yahoo.com.br 
sujeito de apaziguar sua própria consciência a partir de punições autoinfligidas, em detrimento de punições externas, culminando, muitas vezes, no suicídio. Os desejos autodestrutivos surgem como uma resposta ao desejo de destruição da cultura. $\mathrm{O}$ desejo de autocastração exposto abertamente por pacientes psicóticos refere-se à tentativa de permanecer vivo em detrimento dos órgãos condenados.

Menninger encontra na sexualidade elementos autopunitivos necessários "não só para sossegar a consciência, mas para aliviar o medo de punição maior (e possível extinção) por uma autoridade mais alta" (MENNINGER, 1938/2018, p. 134). Percebe-se o teor autopunitivo com que o sujeito lida com seu corpo e com seus desejos. O corpo torna-se objeto passível de destruição. Contudo, "nenhum suicídio é consumado a menos que - além de seu desejo de matar e ser morto - a pessoa suicida deseje também morrer" (MENNINGER, 1938/2018, p. 39). Para o autor, a vitória da destrutividade sobre a criatividade ocorre pelo fracasso da neutralização do ódio pelo amor. Quando "os impulsos autodestrutivos precedem de muito ou suplantam os impulsos construtivos neutralizadores, o resultado é o dramático exemplo de imediata autodestruição conhecido como suicídio" (MENNINGER, 1938/2018, p. 96).

Em seu capítulo sobre drogadicção, mais especificamente sobre alcoolismo, Menninger revela o caráter curativo atribuído ao álcool pelo sujeito drogadicto. A adição do álcool, para Menninger, "pode ser considerada não como uma doença, mas como uma suicida à doença, uma desastrosa tentativa de auto cura do conflito interior invisível, agravado, mas não primordialmente causado (como pensam muitos) por conflito exterior" (MENNINGER, 1938/2018, p. 181). A fuga à destrutividade da vida pela morte atravessa, antes, a tentativa de auto cura. Menninger postula a adição do álcool, tais quais outras toxicomanias, o ascetismo e o martírio, como suicídios crônicos, ou seja, comportamentos autodestrutivos com imenso potencial, inconsciente ou não, para se chegar à morte. Localiza-se, no alcoolismo, o desejo de matar em seu caráter oral: desejo de destruir tudo quanto resiste às exigências do sujeito.

A voracidade da oralidade é muito bem descrita em Luto e Melancolia (FREUD, 1917/1996b). O luto, segundo Freud, se configura pela perda de um ente, de um ideal, de um objeto cujo teor simbólico compõe parte substancial da existência do sujeito. Para manter o objeto vivo e, portanto, livrá-lo de seu invariável fim, é preciso incorporá-lo ao ego de quem sofre sua perda. Agora, o objeto perdido é devorado pelo sujeito, conforme a fase oral do desenvolvimento libidinal.

\section{POLÊM!CA | LABORÉ}


No entanto, contrariando os aparentes objetivos dessa introjeção, o objeto perdido é novamente morto; dessa vez, internamente. A ambivalência que impera as relações interpessoais do sujeito ataca seu próprio ego e, com isso, o objeto a ele integrado. O mesmo ocorre com o amor ou o apaixonamento desmedido: nele, aniquilamos a subjetividade do objeto amado, através de cuidados excessivos que condenam e aprisionam. Esse amor desmedido ocorre no apaixonamento que, fundamentalmente, é aprendido no amor dos cuidadores.

Tanto a melancolia como o luto patológico, para Freud, revelam o desejo de aprisionar para sempre o objeto amado e perdido através de seu aniquilamento final. Sendo assim, aquele que incorpora, aniquila o potencial subjetivo do ser que foi introjetado, fazendo deste uma parte potencial de si mesmo. Observa-se, aqui, o aniquilamento da subjetividade do sujeito antes mesmo de sair do saco gestacional. $\mathrm{O}$ aniquilamento de sua subjetividade pode dar vazão, também, a um desejo de matá-lo em forma de feto e mesmo após o seu nascimento. A vida devorada e preservada é invariavelmente destruída, pois, paralelamente ao desejo de manter vivo o ente perdido, entra em ação a ambivalência do sujeito contra esse mesmo ente, atacandoo por meio de si próprio. Pode-se perceber, então, um dos atributos da ambivalência: a agressividade, que atua com relação à perda nos processos de luto e no desenvolvimento da melancolia.

Contudo, "nem toda agressividade externa tem efeito autodestrutivo" (p. 199), como diz Menninger (1938/2018), ao tratar do comportamento antissocial. Segundo o autor, tal comportamento agrega para si um convite à punição por sucessivos fracassos, provocações e delitos. A autodestruição do comportamento antissocial - que engloba a delinquência, a criminalidade, práticas avessas à moral e geralmente puníveis no âmbito legal - promove a terceirização da autopunição, voltada à incongruência social consciente ou inconscientemente provocada pelo sujeito. Ou seja, o sujeito comete atos criminosos, por exemplo, para suprir um desejo inconsciente de ser punido. Durante a análise de Menninger sobre o suicídio crônico, observa-se que os comportamentos autodestrutivos, principalmente os que se referem à criminalidade, estruturam-se em decorrência de inferências sociais hostis que geram sentimentos ambivalentes de vingança, autoafirmação e culpa (MENNINGER, 1938/2018, p. 217).

A autodestrutividade, nesse contexto, propõe a fuga de uma realidade já aniquilante, e não um aniquilamento total ou parcial do sujeito. A noção de destrutividade deve ser

\section{POLÊM!CA $\mid$ LABORE}


diferenciada da noção de aniquilamento. Enquanto a primeira diz respeito a um comportamento do sujeito com relação ao seu corpo, seus atos e necessárias expiações, o aniquilamento não se limita às investidas do sujeito contra si próprio, mas à atuação das opressões externas na lida do sujeito com o que o constitui. Assim, considera-se a autodestrutividade do suicídio como autolegitimação da vida, na medida em que "Matar-se em lugar de ser executado ou morto pelo destino é conservar em seu íntimo a ilusão de ser onipotente, pois a pessoa é pelo ato e no ato de suicídio senhora da vida e da morte” (MENNINGER, 1938/2018, p. 84).

Tratando do suicídio focal, Menninger desenvolve especificamente o estudo das automutilações. Os mecanismos psicológicos da automutilação equivalem ao suicídio "no sentido de o ódio dirigido contra o objeto externo ter-se voltado contra o eu e ser reforçado com autopunição" (MENNINGER, 1938/2018, p. 248). O suicídio, nesses casos, é substituído por um objeto a ser aniquilado. O objetivo da automutilação está em permitir que o sujeito viva em paz, após uma punição que expie suficientemente suas condenações. A automutilação é, portanto, a aniquilação de uma parte do corpo em prol de todo o resto, ao permitir a continuação das satisfações culpadas e tornar-se, por si própria, uma espécie de satisfação (MENNINGER, 1938/2018).

Retornando às punições provenientes do tabu da masturbação, são localizadas mutilações (roer unhas, por ex.) especificamente como impeditivos e, ao mesmo tempo, substitutos dessa satisfação:

[...] a criança neurótica devido a seu medo de punição deixa de masturbar-se e em lugar disso passa a roer unhas ou a algum outro substituto semelhante, que é regressivo no sentido de retomar aos primeiros dias o meio de prazer, usando a boca em lugar dos órgãos genitais. É, portanto, uma espécie substituta de satisfação e simultaneamente uma punição concomitante, ambas efetuadas de formas atenuadas (MENNINGER, 1938/2018, p. 255).

Muitos ritos de puberdade, que simbolizam a passagem da infância para a vida adulta e propõem uma invariável perda, representam a morte de uma parte pelo todo, mutilações aceitas "pelo superego em lugar da autocastração que sem elas seria exigida" (MENNINGER, 1938/2018, p. 275). As tentativas de cortar certas partes do corpo simbolizam a privação da sexualidade, sendo a área danificada a representante dos órgãos sexuais. Dessa forma, entendese a automutilação como substituta da autocastração.

\section{POLÊM!CA $\mid$ LABORE}


Na medida em que tal sintoma, isto é, tal acomodação, é efetuado, obtém-se uma paz relativa. A (sic) sintoma (mesmo uma mutilação) é, portanto, uma tentativa de auto cura ou pelo menos de auto conservação (MENNINGER, 1938/2018, p. 285).

Com isso, a automutilação é concebida como um suicídio parcial, evitando, assim, o suicídio total. Embora todos estejam suscetíveis a esta forma inconsciente de descarga das pulsões sexuais no próprio corpo, que passa a ser investido como objeto, ou em objetos externos que são simbolicamente sexualizados, há diferenças entre as mutilações direcionadas à mera descarga sexual e as voltadas à expiação sacrificial de fantasias sexuais.

A automutilação, para Menninger, resulta de um conflito entre os impulsos destrutivos agressivos, impulsionados pelo supereu, e a vontade de viver, "com o que uma autodestruição parcial ou local serve ao propósito de satisfazer impulsos irresistíveis e ao mesmo tempo evitar suas consequências psicológicas, mas previstas" (MENNINGER, 1938/2018, p. 299). A satisfação provém não somente da possibilidade de se masturbar, por exemplo, como um ato repreensível pela cultura, mas sim da própria punição a qual o sujeito se submete. Ao permitir a continuação das satisfações culpadas, a punição se torna por si própria uma espécie de satisfação (MENNINGER, 1938/2018, p. 253). Nesse sentido, é possível compreender a automutilação como "uma formação conciliatória para evitar aniquilamento total, isto é, suicídio", sendo, portanto, "uma vitória, embora às vezes custosa, do instinto de vida sobre o instinto de morte" (MENNINGER, 1938/2018, p. 299).

Apesar dos avanços deste estudo em tirar a automutilação de uma ótica unicamente destrutiva e prejudicial, talvez seja interessante questionar o que ela pode significar para o sujeito que a cometeu, antes de lhe ser atribuída um sentido prévio. A automutilação é concebida nos campos médicos como o sintoma de um transtorno ou um transtorno em si. Tal concepção silencia o significado dessa prática, uma vez limitando-a à patologia (ARAUJO et al., 2016, p. 513-514). Determinar a automutilação somente como substituta da castração ou como anormalidade restringe a experiência do sujeito, diante de amplas possibilidades de lida com o próprio corpo e com a vida. O que se pode concluir do estudo de Menninger sobre as automutilações é que há uma série de comportamentos catalogados como autodestrutivos, mas que, ao mesmo tempo, evitam essa mesma destruição. Uma vez a automutilação configurandose como um suicídio parcial, atribui-se a essa categoria de suicídio a mesma qualidade.

Comportamentos suicidas, destrutivos e mórbidos não devem ser interpretados unicamente como uma busca desenfreada pela morte, mas, talvez, como a tentativa de se criar

\section{POLÊM!CA $\mid$ LABORE}

Polêmica - Revista Eletrônica da Uerj - Rua São Francisco Xavier, 524, $1^{\circ}$ andar bloco D, sl.1001 • Tels.: +55 21 2334-4088 / 4087 • http://www.e-publicacoes.uerj.br/index.php/polemica/index http://www.labore.uerj.br • laboreuerj@yahoo.com.br 
novas possibilidades de vida, em um meio que, em vida, essas possibilidades são continuamente negadas. A análise de categorias de suicídios foi necessária para teorizar acerca dos comportamentos socialmente repudiados e postos no mesmo patamar, porém com significados diversos. Neste tópico, foram vistos, então, os aspectos sociais da busca pela morte, sendo necessário estudar a busca ilimitada, e geralmente violenta, pela vida.

\section{Conclusão}

Procurou-se mostrar, ao longo do texto, que a concepção autodestrutiva atribuída a uma série de comportamentos deve ser levada em conta concomitantemente aos seus resultados: a evitação da destruição. O suicídio é compreendido, neste artigo, não como uma simples fuga à realidade ou um aniquilamento do corpo, mas como uma tentativa de se destruir para não se aniquilar. Considera-se, portanto, que a intenção desses comportamentos, apesar do choque com o qual eles são recebidos socialmente, é a preservação da vida.

Elisabeth Kluber-Ross guia a estruturação desta conclusão com seus estudos sobre a relação de pacientes terminais, seus médicos e sua família com a possibilidade e proximidade da morte. Em seu livro Sobre a morte e o morrer, a autora percebe a grande dificuldade que atravessa tanto os pacientes quanto os médicos e os familiares, ao se tratar da morte próxima. Contar o resultado de um exame ou dividir a notícia com o paciente, como sugere a autora, se mostra como um grande desafio para muitos profissionais.

A repulsa que diversos povos e culturas sentem com relação à morte deve-se à incapacidade de nosso inconsciente de vislumbrar a morte como uma possibilidade (KLUBERROSS, 1969/1981, p. 13). A autora ressalta que "o homem, basicamente, não mudou. A morte constitui ainda um acontecimento medonho, pavoroso, um medo universal, mesmo sabendo que podemos dominá-la em vários níveis” (KLUBER-ROSS, 1969/1981, p. 16), acrescentando que a mudança efetiva de nossa sociedade "foi nosso modo de conviver e lidar com a morte, com o morrer e com os pacientes moribundos" (KLUBER-ROSS, 1969/1981, p. 16).

Nossa sociedade encara a morte como um tabu, afasta as crianças do que seria o resultado final de uma existência. Assim, após a morte de um ente, a criança percebe a mudança na dinâmica familiar. Dependendo de sua idade e personalidade, ela pode ser acometida de um sentimento profundo de falta e desorientação, guardando a memória e o peso da perda como uma experiência terrível (KLUBER-ROSS, 1969/1981). O ocultamento da morte produz o

\section{POLÊM!CA | LABORE}

Polêmica - Revista Eletrônica da Uerj - Rua São Francisco Xavier, 524, $1^{\circ}$ andar bloco D, sl.1001 • Tels.: +55 21 2334-4088 / 4087 • http://www.e-publicacoes.uerj.br/index.php/polemica/index http://www.labore.uerj.br • laboreuerj@yahoo.com.br 
medo, a raiva e a angústia que sentimos por ela. Tais sentimentos não se mantêm estáticos no decorrer da vida, pelo contrário; por cada período de desenvolvimento, a presença - ou distância velada - da morte causa reações distintas.

Como diz Kovács (1992), a morte e a vida se atravessam no decorrer do desenvolvimento vital. É possível tentar se afastar da morte, ignorá-la e esquecê-la. Presenciamos a morte simbólica nos primeiros meses de vida, quando a criança sente a ausência de seus cuidadores e desmente sua onipresença. Essas ausências, para a autora, são vivenciadas como mortes pelo desamparo, pois não há chances de sobrevivência sem este primeiro cuidado. Apesar desse significado forte atribuído à morte, ela contém ainda diferentes possibilidades de significação, por exemplo, "a morte como figura maternal que acolhe, que dá conforto" (KOVÁCS, 1992, p. 3), pois está também associada à relação materna (restrita não à mãe, mas a todos os cuidadores iniciais, porém com essa nomenclatura devido a construções sociais bastante sedimentadas dos papéis binários e normativos de gênero) acolhedora e provedora de alimento e afeto.

A autora percebe que há uma série de medos possíveis direcionados à morte, desde o medo da própria morte, que geralmente está atrelado à especificidade da causa do falecimento, até o medo da condição de putrefação do corpo após a morte. Pela manifestação pungente desses medos, nota-se a presença marcante da morte no decorrer da vida, visto que diferentes medos acometem diferentes períodos de desenvolvimento.

O medo da morte pode conter também o medo da solidão, da separação de quem se ama, o medo do desconhecido, o medo do julgamento pelos atos terrenos, o medo do que possa ocorrer aos dependentes, o medo da interrupção dos planos e fracasso em realizar os objetivos mais importantes da pessoa. São tantos os medos, que algum sem dúvida faz parte de nossa vida (KOVÁCS, 1992, p. 16).

Os temores da morte dependem inteiramente da fase de desenvolvimento do sujeito. A infância, por exemplo, guarda a ideia de reversibilidade da morte. Na medida em que a criança percebe que determinado familiar, animal de estimação, figura pública não retornará à dinâmica e à vida comum, a morte passa a ser temida com ainda mais fervor, dando vida aos impulsos destrutivos da criança. A culpa passa a participar da vida do sujeito, pois ele teme que seus desejos de morte se tornem realidade. Da mesma forma com que pais, familiares, professores e conhecidos se tornam alvos de seus desejos destrutivos, a criança também se insere nos alvos

\section{POLÊM!CA $\mid$ LABORE}


dos desejos destrutivos dos outros, sendo tão vulnerável quanto eles (KOVÁCS, 1992). Tudo isso depende, no entanto, dos reforços e apoios que a criança recebe em seu desenvolvimento.

A morte, para o adulto, tende mais para a conotação de abandono, incitando a raiva pelos outros e por si, com demais sentimentos autodepreciativos. A culpa da infância pode perdurar e alocar-se como o centro de dilemas pessoais, quando a onipotência infantil é fortemente abalada por recorrências violentas. O medo da morte é bastante benéfico no que concerne a autopreservação e a qualidade de vida, como na superação de impulsos destrutivos extremos. Sendo a morte caracterizada "pela interrupção completa e definitiva das funções vitais de um organismo vivo, com o desaparecimento da coerência funcional e destruição progressiva das unidades tissulares e celulares" (KOVÁCS, 1992, p. 10), compreende-se que a autopreservação da vida "implica um esforço contra as forças de desintegração, um estímulo para o funcionamento biológico normal” (KOVÁCS, 1992, p. 23).

O medo da morte tem um lado vital, que nos protege, permite que continuemos nossas obras, nos salva de riscos destrutivos e autodestrutivos. Esse mesmo medo pode ser mortal, na medida em que se torna tão potente e restritivo que, simplesmente, a pessoa deixa de viver para não morrer, mas, se observarmos mais atentamente teremos um morto diante de nós que se esqueceu de morrer (KOVÁCS, 1992, p. 26).

Este "viver como se estivesse morto" pode ser identificado como uma morte simbólica, na qual o sujeito se incrusta em si mesmo a fim de evitar situações de morte. Tal comportamento neurótico não reduz a possibilidade de falecimento, pelo contrário: estreita o sujeito com a própria morte ao limitar sua produção de vida, diminuindo seu potencial criativo e social.

Este distanciamento se configura como um mecanismo de defesa aos impulsos destrutivos. Dentre eles, identifica-se a repressão e a negação (KOVÁCS, 1992). A repressão, na medida em que o sujeito deve manter calados os sentimentos de luto - afinal, a manifestação da dor realça a perda e a mortalidade -, a sociabilidade - que impele à vulnerabilidade -, as relações intrapessoais; e negação, perpetuada pela onipotência e imortalidade infantil, de que não somente os outros, mas o próprio sujeito não é imune à finitude.

Os rituais de morte de nossa cultura são polidos a fim de poupar as crianças e toda a estrutura familiar. A polidez que circunda os rituais de morte produz uma morte polida, inacessível. Tal polidez ao redor da morte é o que coloca a própria morte e o suicídio como tabus em nossa cultura, condenando o debate sobre o tema ao lugar de um impossível, restando, apenas, falar sobre prevenção ao suicídio e valorização da vida como vieses legitimados. A

\section{POLÊM!CA $\mid$ LABORE}


inacessibilidade da morte impede que as pessoas entrem em contato com seu próprio fim, evitando-o quando se trata dos outros e negando-o quando se trata de si.

O que a cultura denuncia - e a clínica escuta - é que não dar espaço para que se fale sobre o desejo e a possibilidade de morrer é um fator que coopera pela persistência e perseverança do sujeito em sustentar esse desejo como a única ou uma das poucas formas de existir: na fantasia, o desejo de morrer comparece de forma incessante, para muitos. Portanto, não legitimar um lugar mais franco ou honesto para se falar e escutar sobre morte e suicídio é o que mais mata. Fantasiar ou simplesmente ser invadido por um pensamento suicida é tão humano quanto o desejo de viver.

O tabu da morte se sustenta no que o rodeia. Para Kluber-Ross (1969/1981), o morrer "se torna um ato solitário e impessoal porque o paciente não raro é removido de seu ambiente familiar e levado às pressas para uma sala de emergência" (p. 19), desconectando-se forçosamente de sua realidade. O desconforto que a morte nos traz carrega consigo as circunstâncias que imputamos a ela.

Com o desenvolvimento tecnológico/biomédico, observa-se a regulação rigorosa da vida, dos corpos, tirando do sujeito seu poder de escolha, a posse de si mesmo. Se o suicídio, em termos brutos, é a fuga de uma realidade aniquilante, regular a vida do sujeito de forma a mantê-lo vivo a qualquer custo é, em suma, matá-lo. O futuro de nossa sociedade descrito por Kluber-Ross revela um contexto em que "as pessoas são cada vez mais 'mantidas vivas', tanto com máquinas que substituem órgãos vitais, como com computadores que as controlam periodicamente para ver se alguma função fisiológica merece ser substituída por equipamento eletrônico" (KLUBER-ROSS, 1969/1981, p. 27). O que mais se aproxima do "manter a vida" senão a automutilação, que promove a destruição do corpo em detrimento do aniquilamento do sujeito?

No que diz respeito à eutanásia, Kluber-Ross (1969/1981, p. 33) aponta que "podemos ajuda-los [aos pacientes terminais] a morrer, tentando ajuda-los a viver, em vez de deixar que vegetem de forma desumana". A partir disso, fica mais nítido o desespero para se manter a vida e o medo de se deparar com a morte do outro, sendo ela um reflexo de nossa própria morte. Relatando o processo terapêutico de uma paciente, a autora conclui que somente "o trabalho persistente e contínuo do terapeuta que lidou suficientemente com o seu próprio complexo de

\section{POLÊM!CA $\mid$ LABORE}


morte é que ajuda o paciente a vencer a ansiedade e o medo da morte iminente" (KLUBERROSS, 1969/1981, p. 58).

\begin{abstract}
Embora todo homem, por seus próprios meios, tente adiar o encontro com estes problemas e estas perguntas enquanto não for forçado a enfrentá-los, só será capaz de mudar as coisas quando começar a refletir sobre a própria morte, o que não pode ser feito no nível de massa, o que não pode ser feito por computadores, o que deve ser feito por todo ser humano individualmente (KLUBER-ROSS, 1969/1981, p. 29).
\end{abstract}

O tópico da argumentação mostra que a cultura se constitui por aspectos punitivos e destrutivos que, introjetados pelo sujeito, operam de forma a aniquilar determinados comportamentos - ou aniquilando-o como um todo, dependendo do quão repudiante ele se apresenta na cultura. Analisar o fenômeno do suicídio, com Menninger, é analisar os aspectos suicidas da própria cultura. Como se faz para prevenir a morte naqueles que não encontram lugar para existir senão através da morte? Se a cultura é suicida em si mesma, como falar de prevenção ao suicídio?

O lugar que o suicídio ocupa em nossa sociedade relaciona-se à forma como lidamos com a morte. O suicídio, tal qual a vida e a morte, é também produto da cultura. Se a morte é concebida como algo a ser evitado, temido, não-dito, e a vida como algo a ser desesperadamente preservado, o que se pode pensar do suicídio, que foge às investidas da preservação da vida e busca pelo que mais se tenta negar? Se a morte é o aniquilamento em si, qual a lógica de fugir de uma vida aniquilante pelo suicídio?

Como visto em Fink (1998), a realidade que se apresenta ao sujeito não se dissocia das atribuições culturais de significado. Os significados atribuídos à vida, às escolhas e aos rumos tomados em seu decorrer, são filtrados pelos significados culturais do que é a vida. Sendo assim, é possível utilizar a mesma lógica ao falar da morte. Se a vida é, em si, construída - na invasão do corpo do bebê logo após seu nascimento, atribuindo-lhe determinados brinquedos e brincadeiras, futura carreira e família, sem nem mesmo conhecer o sujeito sobre o qual nos debruçamos; na tomada de decisões do decorrer da vida; nas concordâncias e contravenções às normas sociais -, a morte também é.

Legitimando o discurso sobre a morte, os desejos de morrer e de matar, como desenvolvidos por Menninger, legitima-se o discurso da vida, na medida em que possibilita que o sujeito produza também um discurso sobre o desejo de viver.

\title{
POLÊM!CA $\mid$ LABORE
}


Se todos pudéssemos começar admitindo a possibilidade de nossa própria morte, poderíamos concretizar muitas coisas, situando-se entre as mais importantes o bemestar de nossos pacientes, de nossas famílias e talvez até de nossos pais (KLUBERROSS, 1969/1981, p. 29).

Provavelmente o bem-estar do próprio sujeito. Recorreu-se a Kluber-Ross exatamente pela proximidade da morte do sujeito com a morte do outro. A relação que familiares e médicos constroem, respectivamente, em cima da morte de parentes e pacientes, atinge intimamente a forma com que a família e a equipe médica lidam com a inevitável finalização de suas vidas. Seguindo pela mesma lógica, pode-se conceber o desejo de matar, analisado no tópico da argumentação, como uma tentativa de negar a morte em si afirmando-a no outro, de tão exasperadora que é a realidade. "Se não podemos negar a morte", segundo a autora, "pelo menos podemos tentar dominá-la" (KLUBER-ROSS, 1969/1981, p. 24).

Considerando, como colocado na introdução, que a vida e a morte são processos da consciência, compreende-se que falar da morte não se dissocia tanto dos discursos referentes à vida, pelo contrário. Talvez, se o sujeito aceitasse e encarasse a realidade de sua própria morte, ele aceitaria o desejo de morrer do outro e legitimaria sua vontade e experiência, conferindolhe a posse de si mesmo e de sua vida. Talvez, assim, seja proporcionada ao sujeito outra possibilidade que não o suicídio.

\section{Referências}

ARAÚJO, Juliana Falcão Barbosa de; CHATELARD, Daniela Scheinkman; CARVALHO, Isalena Santos; VIANA, Terezinha de Camargo. O corpo na dor: automutilação, masoquismo e pulsão. Estilos da clínica, São Paulo, v. 21, n. 2, p. 497-515, ago. 2016. Disponível em: http://pepsic.bvsalud.org/scielo.php?script=sci_arttext\&pid=S1415-71282016000200012. Acesso em: 26 fev. 2020.

FINK, Bruce. O sujeito lacaniano: entre a linguagem e o gozo. Rio de Janeiro: Jorge Zahar Ed., 1998.

FREUD, Sigmund. (1915). As pulsões e suas vicissitudes. Rio de Janeiro: Imago, 1996a. (Edição Standard Brasileira das Obras Psicológicas Completas, v. XIV).

FREUD, Sigmund. (1917). Luto e Melancolia. Rio de Janeiro: Imago, 1996b. (Edição Standard Brasileira das Obras Psicológicas Completas, v. XIV).

KLUBER-ROSS, Elisabeth. Sobre a morte e o morrer. São Paulo: Martins Fontes, 1981.

KOVÁCS, Maria Júlia. Morte e desenvolvimento humano. São Paulo: Casa do Psicólogo, 1992.

MENNINGER, Karl Augustus. (1938). Eros e Tanatos: o homem contra si próprio. São Paulo: IBRASA, 2018.

\section{POLÊM!CA $\mid$ LABORE}


Recebido em: 01/03/2020.

Aceito em: 30/04/2020.

\section{POLÊM!CA $\mid$ LABORẸ}

Polêmica - Revista Eletrônica da Uerj - Rua São Francisco Xavier, 524, $1^{\circ}$ andar bloco D, sl.1001 • Tels.: +55 21 2334-4088 / 4087 • http://www.e-publicacoes.uerj.br/index.php/polemica/index http://www.labore.uerj.br • laboreuerj@yahoo.com.br 